\title{
Hexabromocyclododecanes in soils and plants from a plastic waste treatment area in North China: occurrence, diastereomer- and enantiomer-specific profiles, and metabolization
}

\author{
Honglin Huang ${ }^{1}$ (D) • Dan Wang ${ }^{1,2} \cdot$ Weining Wan $^{1} \cdot$ Bei Wen ${ }^{1}$
}

Received: 26 April 2017 / Accepted: 19 July 2017 / Published online: 27 July 2017

(C) Springer-Verlag GmbH Germany 2017

\begin{abstract}
Plastic waste is a source of organic contaminants such as hexabromocyclododecanes (HBCDs). HBCDs have been found to cause developmental and reproductive toxicity; it is important to investigate the occurrence and metabolization of HBCDs in the soil environments with plastic waste contamination. This work analyzed HBCDs and their metabolites in soil and plant samples collected from Xinle and Dingzhou - the major plastic waste recycling centers in North China. Results showed that total HBCD concentrations in soils followed the order: plastic waste treatment site $(11.0-624 \mathrm{ng} / \mathrm{g})>$ roadside $(2.96-85.4 \mathrm{ng} / \mathrm{g}) \geq$ farmland $(8.69-55.5 \mathrm{ng} / \mathrm{g})$. HBCDs were detected in all the plant samples with total concentrations ranging from 3.47 to $23.4 \mathrm{ng} / \mathrm{g}$. $\gamma$-HBCD was the dominant congener in soils, while $\alpha$-HBCD was preferentially accumulated in plants. Compositions of HBCD isomers in soils and plants were significantly different $(P<0.05)$ among sampling sites and among plant species. HBCDs in farmland soil and all plant samples exhibited high enantio-selectivity based on the enantiomeric fractions (EFs). Furthermore, metabolites of pentabromocyclododecenes (PBCDEs) were frequently identified in soils, and mono-
\end{abstract}

Responsible editor: Hongwen Sun

Electronic supplementary material The online version of this article (doi:10.1007/s11356-017-9792-9) contains supplementary material, which is available to authorized users.

Honglin Huang

hlhuang@rcees.ac.cn

1 State Key Laboratory of Environmental Chemistry and Ecotoxicology, Research Center for Eco-Environmental Sciences, Chinese Academy of Sciences, P. O. Box 2871, Beijing 100085, China

2 University of Chinese Academy of Sciences, Beijing 100049, China
OH-HBCDs were the most common ones in plants. This study for the first time provides evidences of HBCD contamination in the soil-plant system caused by plastic waste, their stereoselectivity, and metabolization behavior, improving our understanding of the environmental behavior and fate of HBCDs.

Keywords Plastic waste $\cdot$ HBCDs $\cdot$ Soil $\cdot$ Plant

\section{Introduction}

Tremendous amount of plastic waste are generated and released into the environment due to the widespread use of plastic products (Thompson et al. 2009). The plastic waste issue is even more prominent in China, because China receives 56\% (by weight) of the global imports of waste plastics (Velis 2014). A wide range of organic additives are added into plastic products to achieve certain functionality, including UV stability, elasticity, and flame retardants (Horton et al. 2017). The additives are susceptible to remobilization, because they are generally weakly bound to the plastic matrix. Therefore, plastic wastes that are not properly managed will be sources of organic contaminants. To date, the majority of research has been focusing on the occurrence and toxicological effects of plastics in the marine ecosystems (Cozar et al. 2014; Avio et al. 2016). Although many of the additives such as polybrominated diphenyl ethers (PBDEs) and hexabromocyclododecanes (HBCDs) are identified as either toxic or endocrine disruptors; transporting and releasing of them from the plastics to the environment and then to the organisms is often overlooked (Tang et al. 2014).

HBCDs have been extensively used as additive flame retardants in plastic materials, with their content ranging from 0.5 to $7 \%$ depending on the type of plastic (Alaee et al. 2003). For example, the concentration of HBCDs in expanded 
polystyrene - one of the most widely used plastics, is at the range of 106-960,000 ng/g (Rani et al. 2014). HBCDs are physically embedded in the plastics, instead of being chemically bound, thus can be easily released from the host products into the environment. High levels of HBCD emission from plastic wastes during incineration and thermal treatments have been observed in simulated experiments performed in the lab (Ni et al. 2016; Heeb et al. 2010). HBCDs are stereochemically diverse, which have six diastereomeric pairs of enantiomers and four meso forms (Law et al. 2005). The diastereomeric and enantiomeric composition of HBCDs might be altered when the stereoisomers are subjected to biochemical processes (Liu et al. 2009). Many studies have shown that HBCDs exhibit high diastereo- and enantioselectivity in the environment and biota (Gregg et al. 2008; He et al. 2010; Du et al. 2012). Diastereomers and enantiomers of HBCDs have different biological effect and environmental fate (Law et al. 2005). Therefore, it is necessary to understand the fractionation behavior of HBCDs, not only at diastereomer but also at enantiomer levels. Furthermore, it has been found that HBCDs in the environment are susceptible to photolysis and pyrolysis (Heeb et al. 2008, 2010), enzymatic degradation (Palace et al. 2008; Erratico et al. 2016), and soil microbial degradation (Davis et al. 2005; Le et al. 2017). Since metabolites of many organic compounds possess higher toxicity compared with their parent compounds (Hakk and Letcher 2003), it is also valuable to study the metabolization of organic contaminants in the biota and environment.

Soil is a major environmental sink for all types of plastic wastes (Lwanga et al. 2016). Soils with plastic waste accumulation potentially contain high concentrations of plastic additives. Polychlorinated biphenyls (PCBs), PBDEs and organophosphate esters (OPEs) have been detected at concentrations from nanograms per gram to micrograms per gram in the soils from plastic waste recycling and disposal sites (Teuten et al. 2009; Tang et al. 2014; Wan et al. 2016). In comparison, no studies were devoted to understanding the release of HBCDs into the soil environment caused by plastic waste disposal and recycling activities. Organic pollutants in soils can be accumulated by plants and enter the food chain. It has been found that HBCDs can be diastereo- and enantio-selectively taken up by plants such as maize, wheat, cabbage, and radish, based on pot experiments ( $\mathrm{Li}$ et al. 2011; Zhu et al. 2016; Huang et al. 2016). Compared to greenhouse hydroponic experiments using artificially polluted soils, field studies on sites with plastic wastes may provide more informative and relevant information regarding the weathering and metabolization behavior of HBCDs. To our knowledge, only two studies have targeted on the accumulation of HBCDs in plants from a natural wetland conservation area and a site in the vicinity of an expanded polystyrene material manufacturing factor in Tianjin, China (Zhang et al. 2013; Zhu et al. 2017), but the metabolization behaviors were not addressed. Therefore, in order to better understanding the environmental fate of HBCDs, it is necessary to study the HBCD diastereomer and enantiomer profiles, and their metabolization in the soil-plant system.

The present work was carried out in the two plastic waste recycling sites located in Dingzhou and Xinle County in Hebei Province in Northern China. Soils from the plastic waste treatment sites, the nearby roadside, and the farmland were collected to investigate the effects of plastic waste recycling activities on the release and transport of HBCDs. Vegetables and crops were collected from the farmland to study the uptake of HBCDs by plant and to evaluate the risk of their entering into the food chain. Analysis was performed to characterize the diastereomer and enantiomer profiles of HBCDs, and their metabolization in soils and plants. Results of this study substantiate HBCD contamination in the soilplant system as a result of plastic waste disposal and recycling, the stereo-selectivity, and metabolization behaviors.

\section{Materials and methods}

\section{Sample collection}

The soil and plant samples were collected in 14 towns or villages around Dingzhou $\left(38^{\circ} 30^{\prime} \mathrm{N}, 115^{\circ} 00^{\prime} \mathrm{E}\right)$ and Xinle $\left(38^{\circ} 33^{\prime} \mathrm{N}, 114^{\circ} 67^{\prime} \mathrm{E}\right)$ County, where crude material and chemical recycling of plastic waste has been practiced intensively for about 30 years, mostly operating from small family workshops. Plastic waste that has been recycled in the study area is mainly comprised of expanded polystyrene and extruded polystyrene foams, rubber tires, and wires. The uncontrolled plastic waste processing sites were located on or within $500 \mathrm{~m}$ away from the farmland where vegetables and crops were planted. Intensive plastic waste activities have resulted in plastic scraps dumped onto the road or near the farmlands. A total of 34 surface soil samples including 14 samples from the plastic waste treatment sites, 12 samples from the nearby roadside located within $100-200 \mathrm{~m}$ away from the plastic waste recycling and treatment sites, and 8 samples from the farmlands outside the road 150-300 m were collected in June 2015 by using a stainless-steel shovel at a depth of $0-10 \mathrm{~cm}$. Whole plant samples including crops of maize (Zea mays) and wheat (Triticum aestivum L.), and vegetable of potato (Solanum tuberosum L.), Chinese leek (Allium tuberosum), spinach (Spinacia oleracea), lettuce (Lactuca sativa) and garlic (Allium sativum L.) were collected from the farmland and divided into root and shoot tissues. The detailed geographic information and their abbreviated names of the sampling locations are given Table S1 in Supporting Information. Each soil or plant sample was a composite of four subsamples. Soil and plant samples were freeze-dried, 
ground with agate mortar, and stored at $-20{ }^{\circ} \mathrm{C}$ until further chemical analysis.

\section{Sample extraction and instrument analysis}

Surrogates of ${ }^{13} \mathrm{C}-\alpha$-HBCD and ${ }^{13} \mathrm{C}-\gamma$-HBCD were added into 5-10-g soil and plant samples. Extraction, cleanup, and analysis of HBCDs and their metabolites were performed following methods described by Huang et al. (2016). In brief, the samples were subjected to Soxhlet extraction at $65{ }^{\circ} \mathrm{C}$ for $24 \mathrm{~h}$ using $150 \mathrm{~mL}$ of hexane/dichloromethane. All the concentrated extracts were cleaned and fractionated on a $10-\mathrm{mm}$ i.d. silica gel/alumina column. Concentrations of $\alpha-, \beta-, \gamma-, \delta$-, and $\varepsilon$-HBCDs were determined by an Acquity UPLC-MS/MS (Waters, Milford, MA) equipped with an electrospray interface in negative ionization mode. Matrix effects on signal intensity of UPLC-MS/MS were minimized using ${ }^{13} \mathrm{C}-\beta-\mathrm{HBCD}$ as internal standard. A Waters Acquity column, UPLC BEH C18 $(50 \times 2.1 \mathrm{~mm}$, i.d., $1.7 \mu \mathrm{m}$ particle size $)$ and a Nucleodex $\beta$-PM column (5 $\mu \mathrm{m}, 200 \mathrm{~mm} \times 4 \mathrm{~mm}$ i.d.) were used to separate HBCD diastereomers and enantiomers, respectively. Metabolites of HBCDs in soil and plant samples was identified by an Agilent 6545 Q-TOF LC-MS (Santa Clara, CA) operated with an ESI source in negative ion mode. The $[\mathrm{M}-\mathrm{H}]^{-}$brominated clusters for the putative metabolites of HBCDs were monitored.

\section{QA and QC}

Quality assurance and quality control were conducted by regular analysis of one laboratory blank sample, one standardspiked blank sample, and one standard-spiked matrix sample run with each batch of 10 samples. Blank samples were spiked with $\alpha-, \beta-, \gamma-, \delta-$, and $\varepsilon-H B C D$ isomers at 10,100 , and $200 \mathrm{ng} / \mathrm{g}$. The recoveries of these five isomers were $92.6 \pm 9.5,90.3 \pm 10.5,88.5 \pm 12.6,92.6 \pm 10.9$, and $89.5 \pm 11.8 \%$, respectively. Native HBCD standard mixtures at seven concentration levels were used to obtain a calibration curve with a concentration range of 5-500 $\mu \mathrm{g} / \mathrm{L}$. Method detection limits were $(\mathrm{S} / N=3)$ in procedural blanks for the $\alpha-, \beta-, \gamma-, \delta$-, and $\varepsilon$-isomers were $0.6,0.05,0.2,0.1$, and $0.1 \mathrm{ng} / \mathrm{g}$, respectively. HBCDs in the blank soils and plants were below the limit of detection.

\section{Data treatment}

The mobile phase and column bleed may cause the enantiomeric fraction (EF) of chiral HBCDs to deviate from 0.5 (Marvin et al. 2007). When corrected by using ${ }^{13} \mathrm{C}_{12}$-labeled HBCDs, this phenomenon can be effectively avoided (Table S2). EF values were calculated only for soil and plant samples with concentrations of HBCD diastereomers above the limit of detection (LOD) by the following formula:

$\mathrm{EF}=\frac{\mathrm{A}_{+} / \mathrm{A}_{+\mathrm{C} 13}}{\mathrm{~A}_{+} / \mathrm{A}_{+\mathrm{C} 13}+{ }^{\mathrm{A}_{-}} / \mathrm{A}_{-\mathrm{C} 13}}$

where $\mathrm{A}_{+}$and $\mathrm{A}_{-}$are the peak areas of eluted (+)- and (-)enantiomers, respectively. EF values for $\alpha-\beta-$, and $\gamma$ HBCDs $(100 \mu \mathrm{g} / \mathrm{L})$ in an external standard solution were determined to be $0.507 \pm 0.012,0.502 \pm 0.005$, and $0.499 \pm 0.007(n=6)$, respectively. The EFs of $\alpha-, \beta-$, and $\gamma$-HBCDs for the standard-spiked blank QA/QC samples were $0.505 \pm 0.012,0.504 \pm 0.007$, and $0.500 \pm 0.006$ $(n=6)$, respectively, which showed no significant difference from those of the calibration standards $(P>0.05)$. This suggested that no significant enantiomeric fractionation occurred during sample preparation and cleanup. In addition, the presence of $\delta$ - and $\varepsilon$-HBCD and the unidentified compound peaks interfered little with the enantiomeric separation of HBCDs.

Concentrations of HBCDs in samples were expressed on a dry weight basis. All results are expressed as the mean \pm standard deviation (SD) of triplicates. Statistical analysis was performed by SPSS 16.0 variance analysis software. One-way and two-way ANOVAs with Tukey's multiple comparison tests were used to assess differences among samples at $P<0.05$. For samples with HBCD concentrations below LOD were considered as zero. Because no target analytes were detected in blanks, concentrations reported are not blank-corrected.

\section{Results and discussion}

\section{Occurrence of HBCDs in soils and plants caused by plastic waste activities}

Five isomers, $\alpha-, \beta-, \gamma-, \delta$-, and $\varepsilon$-HBCDs, were detected in 34 soil samples collected from the plastic waste treatment sites and the surrounding roadside and farmland. Individual isomers of HBCDs were found at concentrations ranging from below the detection limit (N.d.) to $206 \mathrm{ng} / \mathrm{g} \mathrm{dw}$ for $\alpha$-HBCD, from N.d. to $156 \mathrm{ng} / \mathrm{g} \mathrm{dw}$ for $\beta-\mathrm{HBCD}$, and from 2.63 to $262 \mathrm{ng} / \mathrm{g} \mathrm{dw}$ for $\gamma$-HBCD (Table 1). $\delta$-HBCD and $\varepsilon$-HBCD were detected at very low concentration levels (N.d.- $0.10 \mathrm{ng} /$ $\mathrm{g}$ for $\delta$-HBCD and N.d.-2.47 $\mathrm{ng} / \mathrm{g}$ for $\varepsilon$-HBCD). Concentrations of total HBCDs ( $\Sigma$ HBCD) in soils were summarized (Fig. 1). $\Sigma$ HBCD concentrations of the soil samples clearly showed a spatial-dependent trend: concentrations in samples from disposal/recycling sites are the highest, followed by the roadside soil, and farmland soil the least. $\Sigma$ HBCD concentrations in the soil samples collected from the plastic waste treatment sites ranged from 11 to $624 \mathrm{ng} / \mathrm{g}$ dry weight (dw), with a mean value of $53 \mathrm{ng} / \mathrm{g} \mathrm{dw}$. The open dumping 
Table 1 Concentrations of HBCD diastereoisomers in soils from the plastic recycling areas in Xinle and Dingzhou Country in North China (ng/g)

\begin{tabular}{|c|c|c|c|c|c|c|c|}
\hline & Sampling sites & $\alpha-\mathrm{HBCD}$ & $\beta-\mathrm{HBCD}$ & $\gamma-\mathrm{HBCD}$ & $\delta$-HBCD & $\varepsilon-\mathrm{HBCD}$ & $\Sigma \mathrm{HBCD}$ \\
\hline \multirow[t]{14}{*}{ Plastic disposal site, $\Sigma$ HBCD: $11.0-624$} & FMC & $2.06(0.19)$ & $2.46(0.19)$ & $23.7(2.29)$ & $0.10(0.07)$ & $0.12(0.07)$ & $28.2(2.62)$ \\
\hline & $\mathrm{HC}$ & $21.0(1.98)$ & $12.4(1.21)$ & $43.5(3.90)$ & N.d. & $0.96(0.08)$ & $76.9(6.96)$ \\
\hline & TCP & $11.1(1.07)$ & $3.90(0.21)$ & $6.71(0.75)$ & N.d. & N.d. & $21.7(1.92)$ \\
\hline & $\mathrm{SC}-1$ & N.d. & $2.39(0.19)$ & $18.6(1.76)$ & N.d. & N.d. & $21.0(1.71)$ \\
\hline & DWC & N.d. & $1.33(0.08)$ & $62.9(5.83)$ & N.d. & $1.27(0.11)$ & $64.2(5.87)$ \\
\hline & NJZ & N.d. & $1.84(0.15)$ & $108(7.38)$ & N.d. & N.d. & $110(9.93)$ \\
\hline & $\mathrm{ZC}$ & $23.9(1.54)$ & $13.1(1.22)$ & $16.2(1.67)$ & N.d. & $0.10(0.08)$ & $53.4(5.23)$ \\
\hline & NXXC & $16.7(1.39)$ & $8.53(0.86)$ & $19.5(1.75)$ & N.d. & $1.43(0.11)$ & $44.7(4.07)$ \\
\hline & DSH & $1.25(0.08)$ & $1.42(0.17)$ & $8.32(0.88)$ & N.d. & N.d. & $11.0(1.19)$ \\
\hline & $\mathrm{XC}$ & $17.9(1.46)$ & N.d. & $37.1(3.54)$ & N.d. & N.d. & $55.0(3.75)$ \\
\hline & YHZ & $10.8(1.07)$ & N.d. & $9.42(0.88)$ & N.d. & $0.53(0.08)$ & $20.2(1.59)$ \\
\hline & XWLC & $206(18.6)$ & $156(13.0)$ & $262(13.6)$ & N.d. & $2.47(0.21)$ & $624(48.2)$ \\
\hline & SC-2 & $32.2(2.71)$ & $63.5(5.07)$ & $161(14.4)$ & N.d. & N.d. & $256(18.1)$ \\
\hline & BLJZ & $65.6(5.90)$ & $39.0(3.15)$ & $59.1(5.49)$ & N.d. & $1.64(0.21)$ & $164(12.7)$ \\
\hline \multirow[t]{12}{*}{ Roadside soils, $\Sigma$ HBCD: 2.96-85.4 } & FMC & $0.43(0.05)$ & $2.86(0.31)$ & $8.45(0.78)$ & N.d. & N.d. & $11.7(0.97)$ \\
\hline & $\mathrm{HC}$ & $1.04(0.09)$ & $3.81(0.32)$ & $12.3(1.19)$ & N.d. & N.d. & $17.2(1.26)$ \\
\hline & TCP & $1.27(0.10)$ & $0.66(0.07)$ & $4.94(0.54)$ & N.d. & $0.05(0.01)$ & $6.87(0.51)$ \\
\hline & DWC & $3.86(0.24)$ & $1.39(0.12)$ & $8.79(0.97)$ & N.d. & N.d. & $14.0(1.53)$ \\
\hline & $\mathrm{ZC}$ & $5.09(0.54)$ & $2.97(0.23)$ & $7.52(0.78)$ & N.d. & N.d. & $15.6(1.67)$ \\
\hline & NXXC & $0.49(0.06)$ & $1.76(0.18)$ & $8.88(0.83)$ & N.d. & N.d. & $11.1(1.14)$ \\
\hline & DSH & $1.05(0.08)$ & N.d. & $4.68(0.34)$ & N.d. & N.d. & $5.73(0.47)$ \\
\hline & $\mathrm{XC}$ & $0.23(0.04)$ & $0.10(0.09)$ & $2.63(0.26)$ & N.d. & N.d. & $2.96(0.29)$ \\
\hline & YHZ & $1.08(0.11)$ & $0.24(0.04)$ & $12.4(1.03)$ & N.d. & N.d. & $13.7(1.06)$ \\
\hline & XWLC & $33.4(2.68)$ & $6.49(0.51)$ & $45.5(4.32)$ & N.d. & $0.15(0.07)$ & $85.4(7.35)$ \\
\hline & SC-2 & $26.0(2.05)$ & $3.56(0.38)$ & $25.3(2.72)$ & N.d. & N.d. & $54.9(4.93)$ \\
\hline & BLJZ & N.d. & $2.72(0.17)$ & $50.0(5.50)$ & N.d. & N.d. & $52.7(4.74)$ \\
\hline \multirow[t]{8}{*}{ Farmland soil, $\Sigma$ HBCD: 8.69-55.5 } & FMC & $4.23(0.47)$ & $3.80(0.34)$ & $7.53(0.68)$ & N.d. & N.d. & $15.6(1.64)$ \\
\hline & TCP & N.d. & $0.93(0.08)$ & $7.76(0.84)$ & N.d. & N.d. & $8.69(0.72)$ \\
\hline & DWC & N.d. & $1.45(0.15)$ & $12.8(1.07)$ & N.d. & $0.05(0.01)$ & $14.3(0.79)$ \\
\hline & NJZ & $2.16(0.19)$ & $2.38(0.31)$ & $13.5(1.32)$ & N.d. & N.d. & $18.0(1.52)$ \\
\hline & $\mathrm{ZC}$ & N.d. & $3.63(0.39)$ & $7.81(0.52)$ & N.d. & $0.04(0.01)$ & $11.4(1.23)$ \\
\hline & NXXC & N.d. & $3.15(0.23)$ & $7.70(0.63)$ & N.d. & N.d. & $10.9(0.86)$ \\
\hline & $\mathrm{XC}$ & N.d. & $1.62(0.18)$ & $12.0(0.94)$ & N.d. & N.d. & $13.6(1.06)$ \\
\hline & $\mathrm{SC}-2$ & N.d. & $51.0(4.55)$ & $4.58(0.42)$ & N.d. & $0.10(0.08)$ & $55.5(4.77)$ \\
\hline
\end{tabular}

Standard deviation in parentheses

$N . d$. not detected and lower than the limit of determination

and burning of plastic waste apparently lead to high HBCDs accumulation in the sites. For example, the highest concentration of $\Sigma H B C D(624 \mathrm{ng} / \mathrm{g} \mathrm{dw})$ was at the plastic combustion residue site of Xiwulou, approximately 1-2 orders of magnitude higher than that in the soil from Dashahe $(11 \mathrm{ng} / \mathrm{g} \mathrm{dw})$ (Table 1). The concentrations of $\Sigma \mathrm{HBCD}$ in roadside $(n=12)$ and farmland $(n=8)$ soils around the plastic recycling sites ranged from 2.96-85.4 and 8.69-55.5 $\mathrm{ng} / \mathrm{g} \mathrm{dw}$ (mean 13.6 and $11.2 \mathrm{ng} / \mathrm{g} \mathrm{dw}$ ), respectively. It is worth noting that there was a significant correlation between $\Sigma H B C D$ concentrations in the soils from the plastic waste treatment sites and the corresponding nearby roads and farmlands (Fig. S1, $P<0.005)$. These results obviously indicated that plastic wastes disposal/recycling caused HBCDs release into soils and the surrounding environments.

A comparison of HBCD levels in soils between the previous studies and this study was conducted (Table S3). The levels detected in this study were substantially lower than those reported in surface soil samples collected from point sources near an expanded polystyrene (XPS) producing plant in Sweden (140-1300 ng/g dw) (Remberger et al. 2004) and $\mathrm{HBCD}$ processing plants in Germany and Belgium 


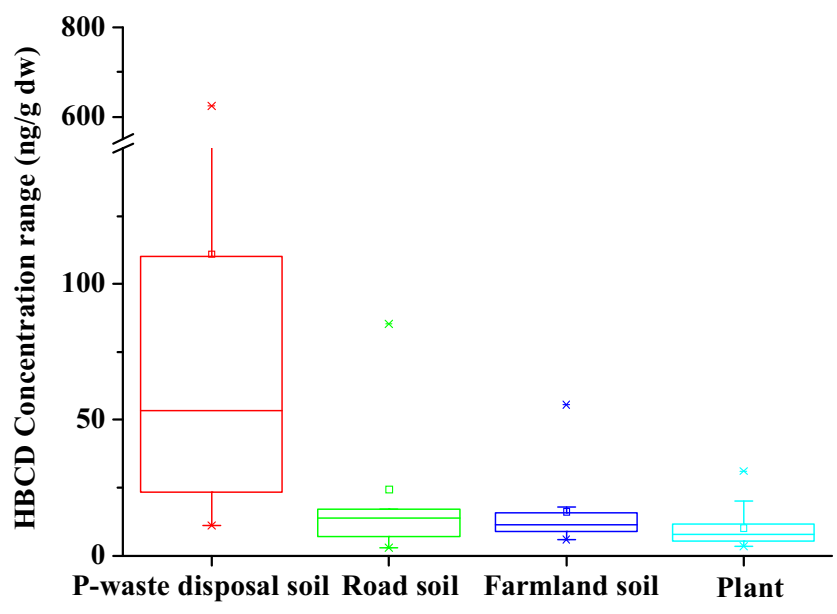

Fig. 1 Box plots for total concentrations of HBCDs in the soils and plants from the plastic recycling areas in Xinle and Dingzhou Country in North China. P-waste represents plastic waste. In this box char, modifier letter minus sign in each box is for median value; white square is for average value; asterisk is for max and min value

(111-23,200 ng/g dw) (Petersen et al. 2004). But they were much higher than those from urban $(1.7-5.6 \mathrm{ng} / \mathrm{g} \mathrm{dw})$ in Guangzhou (Yu et al., 2008), and from the five open e-waste dumping sites in India, Vietnam, Malaysia, Indonesia, and Cambodia (not detected to $2.4 \mathrm{ng} / \mathrm{g} \mathrm{dw}$ ) (Eguchi et al., 2013). Concentration of HBCDs in soils in this study were comparable to those from e-waste recycling areas and industrial areas in South China (Gao et al. 2011) and urban in the UK (Desborough 2011). This suggests that the surface soils in the plastic recycling areas in Dingzhou and Xinle have been suffering from relatively high levels of HBCD pollution.

Alpha-HBCD was the most predominant diastereomer in plants with concentrations ranging from $2.59 \mathrm{ng} / \mathrm{g} \mathrm{dw}$ (spinach shoot from site Yihezhuang) to $16.9 \mathrm{ng} / \mathrm{g} \mathrm{dw}$ (wheat root from site Songcun-2) (Table 2). $\beta$-HBCD is second to $\alpha$-HBCD, with concentration ranging from $0.58 \mathrm{ng} / \mathrm{g} \mathrm{dw}$ in lettuce shoot from Xuancun to $6.52 \mathrm{ng} / \mathrm{g} \mathrm{dw}$ in leek root from Nanjiazhuang. $\gamma$-HBCD was only detected in 11 of 19 plant samples, with the concentration ranging from 0.15 to $6.16 \mathrm{ng} / \mathrm{g}$. Neither $\delta$-HBCD nor $\varepsilon$-HBCD was detected in plants. Concentrations of HBCD in plants in this study ranged from 3.47 to $23.4 \mathrm{ng} / \mathrm{g}$, which varied broadly not only among the sampling sites $(P<0.01)$, but also among the plant species $(P<0.05)$. The leek (Allium tuberosum) root from the open burning site Nanjiazhuang had the highest HBCD concentration $(23.4 \mathrm{ng} / \mathrm{g} \mathrm{dw})$, followed by the wheat root $(20.2 \mathrm{ng} / \mathrm{g} \mathrm{dw})$ from plastic waste disposal site Songcun, and HBCD in the spinach shoot (3.47 $\mathrm{ng} / \mathrm{g} \mathrm{dw}$ ) from Yihezhuang was the lowest. Studies on plant uptake of HBCDs are scarce, and most experiments were conducted in the laboratory ( $\mathrm{Li}$ et al. 2011; Zhu et al. 2016; Huang et al. 2016). HBCD concentrations in plants in this study were comparable to those in radish, wheat, and reed (3-28 $\mathrm{ng} / \mathrm{g}$ ) in a field study by Zhang et al. (2013). The high concentrations of HBCDs in plant samples clearly demonstrated that plastic wastes disposal in the environment can lead to HBCDs entering the food chain.

Table 2 Concentrations of HBCD diastereoisomers in plant samples from the plastic recycling site in Xinle and Dingzhou Country in northern China (ng/g)

\begin{tabular}{|c|c|c|c|c|c|c|}
\hline & Sampling sites & Plants & $\alpha-\mathrm{HBCD}$ & $\beta-\mathrm{HBCD}$ & $\gamma$-HBCD & $\Sigma \mathrm{HBCD}$ \\
\hline \multirow[t]{18}{*}{ Plant $\Sigma$ HBCD: $3.47-23.4$} & \multirow[t]{2}{*}{ SC-1 } & Maize (shoot) & $3.91(0.45)$ & $1.82(0.21)$ & N.d. & $5.72(0.53)$ \\
\hline & & Maize (root) & $6.99(0.58)$ & $2.19(0.21)$ & $1.56(0.07)$ & $10.8(1.20)$ \\
\hline & \multirow[t]{4}{*}{$\mathrm{XC}$} & Potato (shoot) & $3.85(0.27)$ & $1.58(0.12)$ & N.d. & $5.43(0.49)$ \\
\hline & & Potato (root) & $7.83(0.75)$ & $1.86(0.15)$ & $1.79(0.11)$ & $11.6(0.92)$ \\
\hline & & Lettuce (shoot) & $3.88(0.41)$ & $0.58(0.08)$ & N.d. & $4.47(0.43)$ \\
\hline & & Lettuce (root) & $6.62(0.41)$ & $1.57(0.13)$ & $0.15(0.03)$ & $8.44(0.72)$ \\
\hline & \multirow[t]{4}{*}{ YHZ } & Spinach (shoot) & $2.59(0.06)$ & $0.93(0.07)$ & N.d. & $3.47(0.35)$ \\
\hline & & Spinach (root) & $3.77(0.28)$ & $1.90(0.17)$ & $2.11(0.23)$ & $7.78(0.81)$ \\
\hline & & Garlic (shoot) & $5.97(0.49)$ & $0.81(0.09)$ & N.d. & $6.78(0.70)$ \\
\hline & & Garlic (root) & $6.66(0.62)$ & $3.44(0.43)$ & $1.61(0.12)$ & $11.7(0.96)$ \\
\hline & \multirow[t]{2}{*}{ NJZ } & Leek (shoot) & $6.74(0.83)$ & $1.63(0.19)$ & $1.08(0.12)$ & $9.44(0.99)$ \\
\hline & & Leek (root) & $10.4(1.16)$ & $6.52(0.63)$ & $6.16(0.57)$ & $23.4(2.26)$ \\
\hline & \multirow[t]{2}{*}{$\mathrm{ZC}$} & Wheat-1 (shoot) & $3.05(0.32)$ & $2.97(0.25)$ & N.d. & $6.03(0.59)$ \\
\hline & & Wheat-1 (root) & $6.40(0.48)$ & $1.01(0.12)$ & N.d. & $7.42(0.65)$ \\
\hline & \multirow[t]{2}{*}{ DWC } & Wheat-2 (shoot) & $3.16(0.33)$ & $0.96(0.08)$ & N.d. & $4.13(0.45)$ \\
\hline & & Wheat-2 (root) & $5.16(0.47)$ & $0.61(0.07)$ & $0.43(0.05)$ & $6.22(0.64)$ \\
\hline & \multirow[t]{2}{*}{ SC-2 } & Wheat-3 (shoot) & $4.70(0.52)$ & $1.82(0.16)$ & $3.88(0.42)$ & $10.4(0.97)$ \\
\hline & & Wheat-3 (root) & $16.9(1.22)$ & $1.79(0.15)$ & $1.57(0.16)$ & $20.2(2.19)$ \\
\hline
\end{tabular}

There was no $\delta$-HBCD or $\varepsilon$-HBCD detected in plant samples; standard deviation in parentheses

$N . d$. not detected and lower than the limit of determination 


\section{Diastereomer profiles of HBCDs in soils and plants}

The detection frequencies of $\gamma$ - and $\beta$-HBCDs were above $90 \%$, whereas that of $\alpha$-HBCD was less than $67 \%$ in soil samples. The mean percentages of HBCD diastereomers in soils were $17.5,16.2$, and $66.3 \%$ for $\alpha-, \beta-$, and $\gamma-\mathrm{HBCD}$, respectively. $\gamma$-HBCDs exhibited the highest detection frequency and percentage contribution in almost all soils, which is consistent with the evidence that $\gamma$-HBCDs have the highest concentrations in the technical mixtures. Similar results were also reported for soils in manufacturing plants from European countries (Petersen et al. 2004) and Guangzhou, China (Gao et al. 2011). The diastereomer profile of HBCDs can help reveal their mobilization and metabolization behaviors in the environment (Law et al. 2005). Diastereomer profiles of HBCDs in soils from the plastic waste treatment sites varied markedly among the sampling sites (Fig. $2 \mathrm{a}, P<0.05$ ), which might be attributed to the differences of the HBCD isomer compositions in plastic materials and the plastic waste recycling methods (Zhang et al. 2012; Ni et al. 2016). The HBCD isomer composition in soils were significantly different between the plastic waste treatment sites and the corresponding roadside and farmlands (Fig. 2a, b, c, $P<0.05$ ). Moreover, the percentage contributions of $\alpha-, \beta-$, and $\gamma-$ HBCD diastereomers in soils especially for those collected from the plastic burning sites $(37.3-46.0 \% \alpha$-HBCD, 13.9-
$24.7 \% \beta-\mathrm{HBCD}$, and $30.5-43.5 \% \gamma-\mathrm{HBCD})$ and farmland sites (N.d. $-27.2 \% \alpha$-HBCD, $10.2-91.7 \% \quad \beta-\mathrm{HBCD}$, and $8.24-89.8 \% \gamma$-HBCD) were significantly $(P<0.05)$ different from those of the commercial products, which were composed of $1-12 \% \alpha-\mathrm{HBCD}, 10-13 \% \quad \beta-\mathrm{HBCD}$, and $70-89 \% \gamma-$ HBCD. Results from the above showed matrix-dependent diasteromer profiles that can be possibly attributed to stereoselective transport/transformation processes of HBCDs in soil environment (Håkas et al. 2009; Meng et al. 2011). HBCDs in soils would undergo complex processes such as sorption-desorption, leaching and volatilization, these behaviors might be stereoselective (Wong et al. 2012). In addition, diastereomer inter-conversion of HBCDs in soils can occur caused by photolysis and pyrolysis, organism uptake and biodegradation (Heeb et al. 2010; Zhu et al. 2016; David et al. 2005).

The HBCD diastereomer profiles of plants and soils were significantly different $(P<0.01$, Fig. 3$) . \gamma$-HBCD presented as the dominant congener in soils, while $\alpha$-HBCD was preferentially accumulated in plants. Biological factors from plants and their associated microbes were probably responsible for this observation (Zhu et al. 2016). The composition of $\alpha-, \beta-$, and $\gamma$-HBCDs in plants were 44.4-88.1, 8.86-49.3, and N.d.-37.3\%, respectively. Alfa-HBCD has the highest contribution in all the plant samples (Fig. 2d), which was in line with the previous reports on HBCD diastereomer profiles (a)

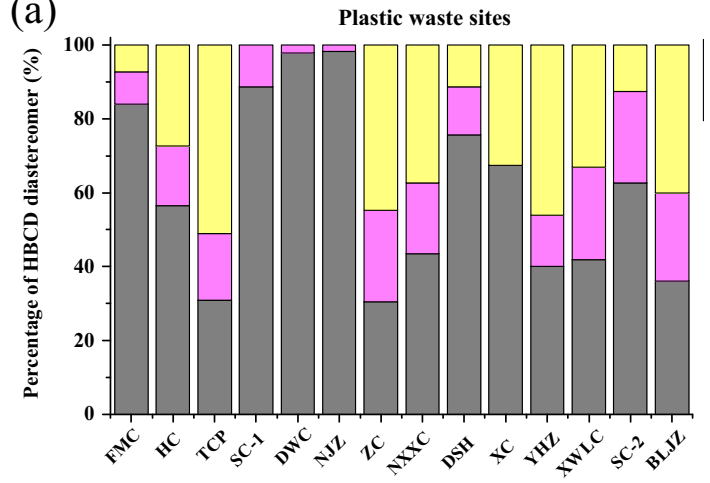

(c)

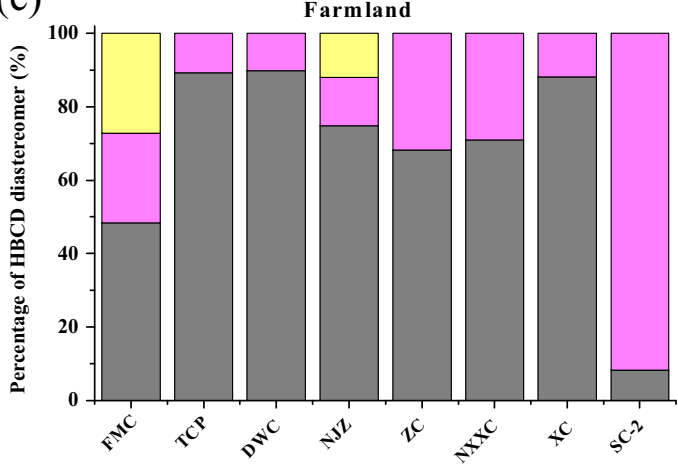

(b)

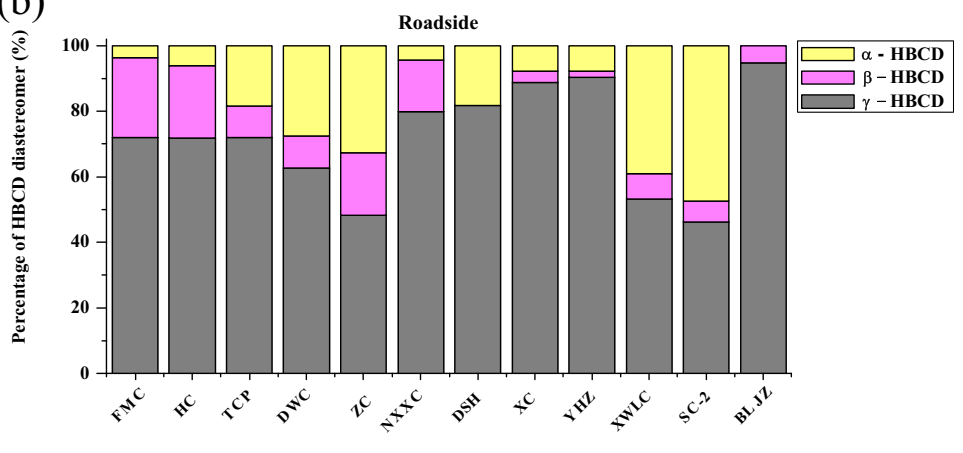

(d)

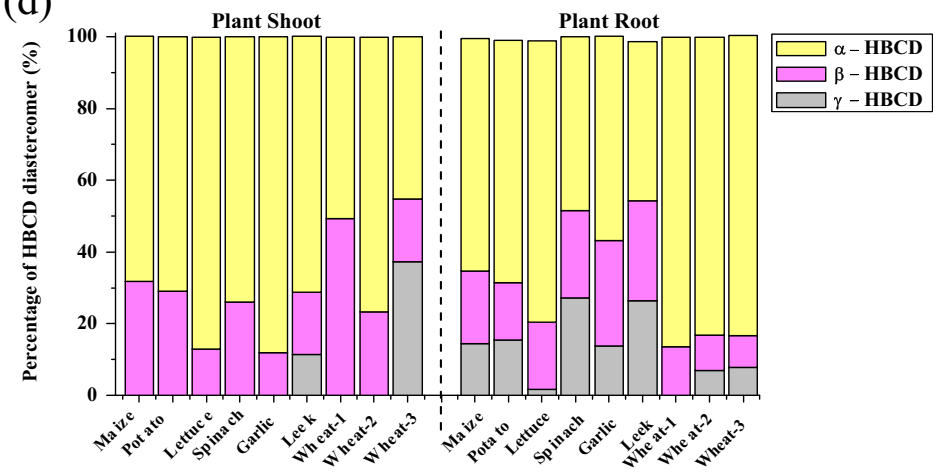

Fig. 2 Percentage profiles of HBCD diastereomers in soil (a-c) and plant (d) samples. The $\delta$ - and $\varepsilon$-HBCD diastereomers were not included because they were only detected in trace amounts in very few samples 

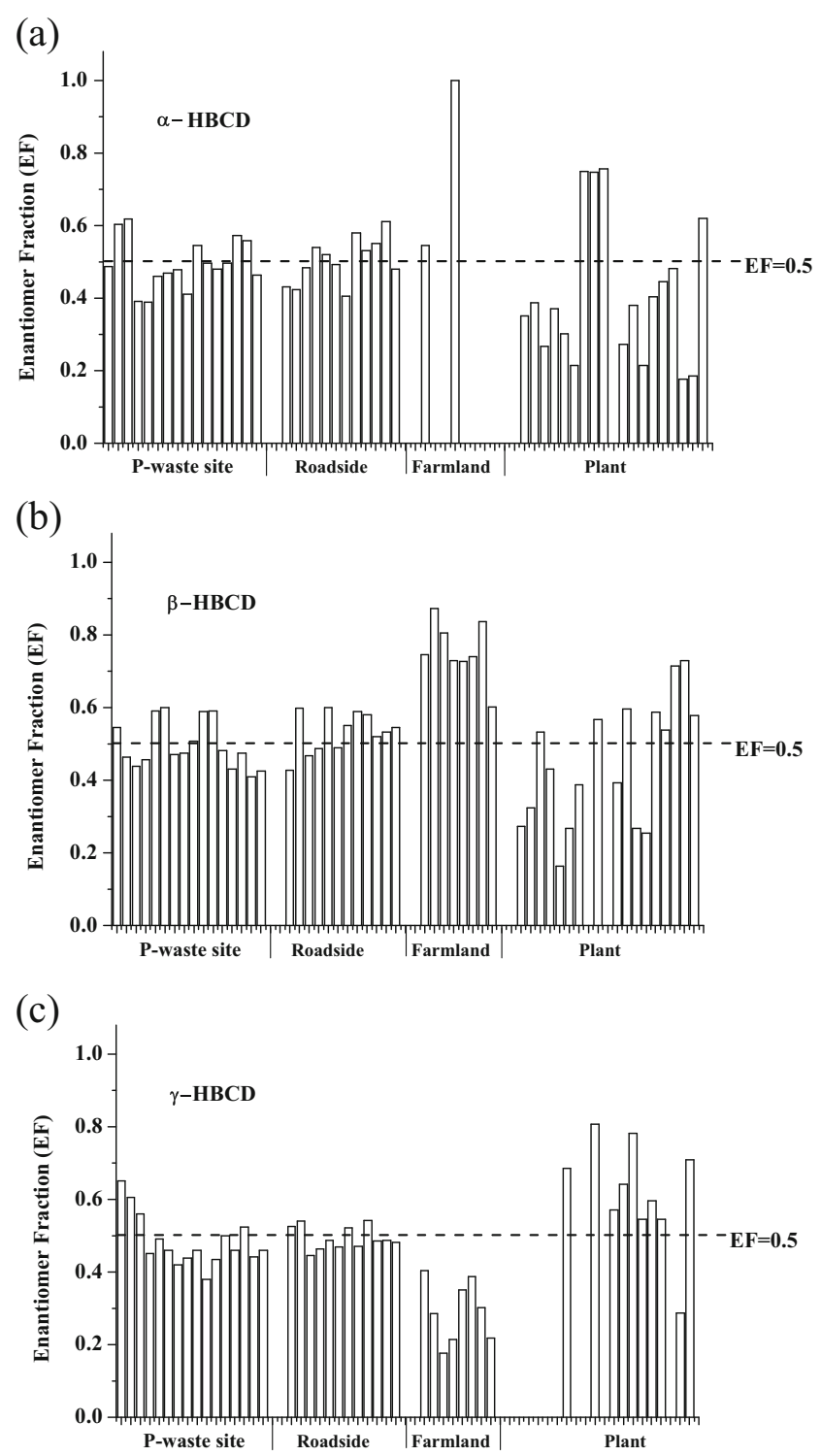

Fig. 3 Enantiomer fractions (EFs) for $\alpha-, \beta-, \gamma$-HBCDs in soils and plants $(\mathbf{a}-\mathbf{c})$ from the plastic recycling areas in Xinle and Dingzhou Country in North China. EFs were calculated only for soil and plant samples with concentrations of HBCD diastereomers above the LOD. $\mathrm{P}$-waste represents plastic waste

in most biota samples including aquatic invertebrates, fish, marine mammals, and birds (Gregg et al. 2008; He et al. 2010; Du et al. 2012). Moreover, HBCD diastereomer profiles also exhibited significant differences among plant species $(P<0.05)$. For example, the percentage contributions of $\alpha-$, $\beta$-, and $\gamma$-HBCD in spinach root collected from the site Yihezhuang were $48.5,24.4$, and $27.1 \%$, respectively, while those in garlic root were $56.9,29.4$, and $13.8 \%$, respectively. The physicochemical properties such as hydrophobicity contributed to the specific plant uptake and translocation of HBCD diastereomers, and HBCD compositions could be changed due to their bioisomerization by plant enzymes ( $\mathrm{Li}$ et al. 2011; Zhu et al. 2016; Huang et al. 2016). The mechanisms responsible for the selectivity of HBCD stereoisomers in plants are not yet fully understood, and further enantiomeric analysis is required.

\section{Enantiomeric enrichment of HBCDs in soils and plants}

The EFs in the soil samples were 0.04-0.618, 0.425-0.748, and $0.214-0.651$ for $\alpha-, \beta-$, and $\gamma$-HBCDs, respectively (Fig. 3). No significant differences $(P>0.05)$ were found between the EF values for most of the soil samples collected from the plastic waste disposal and the nearby roadside sites and those of the standards, except for the EF values of $\alpha$-HBCD at site Tiancunpu and Dawucun, EF values of $\beta$ HBCD at sites of Tiancunpu, Xiwulou, and Songcun-2, and EF values of $\gamma$-HBCD at sites of Fengmingcun, Dawucun, Songcun-2, and Xiwulou. Enantiomeric composition of HBCDs can be thermally rearranged (KÖpen et al. 2008; Heeb et al. 2010). Recycling methods for plastic wastes such as intensive burning and heating may cause the stereoisomerization of HBCD enantiomers, which resulted in the EFs deviating from the standards. Significant differences were found between the EFs in all the farmland soil and those of standards $(P<0.05)$, indicating that enantiomeric selectivity of HBCDs occurred in farmland soils. The concentrations of individual HBCD enantiomer in the farmland soils are given in Fig S2a. A significant enrichment of the (-)-enantiomer was found for $\alpha$ - and $\gamma$-HBCD in farmland soils. However, the (+)-enantiomer seemed more easily to be enriched compared to the (-)-enantiomer for $\beta$-HBCD. To date, only a few studies have investigated the enantiomer fractions of HBCDs in the abiotic environment. Gao et al. (2011) studied the enantiomer-specific profiles of HBCDs in 90 surface soils from two e-waste recycling areas and industrial areas in South China and observed no significant differences in the EF values between the soil samples and the standards. However, Guerra et al. (2008) found that the EF values of HBCDs in sediment samples deviated from the standard values, and the deviation was greater in sites farther away from polluted areas. Furthermore, greater degradation of (+)HBCD than (-)-HBCD for $\gamma$-HBCD in sediments was observed (Wu et al. 2010); the selective degradation of specific HBCD stereoisomers may be caused by the activity of microorganisms (Davis et al. 2005, 2006).

Accumulation and translocation of chiral contaminants in plants exhibit selectivity (Zhai et al. 2014). Field work on enantiomer-specific accumulation of HBCDs by plants is scarce. In this work, EF values for $\alpha$-, $\beta$-, and $\gamma$-isomers in vegetation and crops collected from the farmland nearby the plastic waste recycling sites were altered significantly compared with HBCD standards (Fig. 3). EF values for $\alpha$-HBCD were between $0.176-0.749$. All the EF values for $\alpha-\mathrm{HBCD}$ in plants except wheat were significantly lower than those in standard solution, suggesting that there was a strong 
enrichment of $(-)-\alpha$-HBCD relative to $(+)-\alpha-\mathrm{HBCD}$. EF values for $\beta$-HBCD were $0-0.728$, with a significantly more $(-)$-enantiomer accumulated in 10 plant samples and more (+)-enantiomer accumulated in 8 plant samples. In the case of $\gamma$-HBCD, the EF values were calculated only for 10 plant samples $(0.287-0.807)$. All the EF values for the $\gamma$-isomer in plants, except wheat-3, were higher than those in standard solution $(0.499 \pm 0.007)$, implying that more $(+)-\gamma$-HBCD than $(-)-\gamma-$ HBCD was accumulated in these plants.
Significant changes in EF values of the HBCD diastereomers in the present study mean the occurrence of in vivo enantioselective absorption and/or metabolic processes in plants. Zhang et al. (2013) reported that EF values for HBCDs were significantly different from 0.5 in radish, wheat, and reed from a natural wetland conservation area near Tianjin, China. Enantiomeric enrichment of HBCDs was also observed in several other organisms, such as seals, dolphins, and fishes (Gregg et al. 2008; Susanne et al. 2010; Du et al. 2012), and
Fig. 4 Debrominated and hydroxylated products of HBCDs and their detection frequency (DF) in soils (a) and plants (b) from the plastic recycling areas (a)

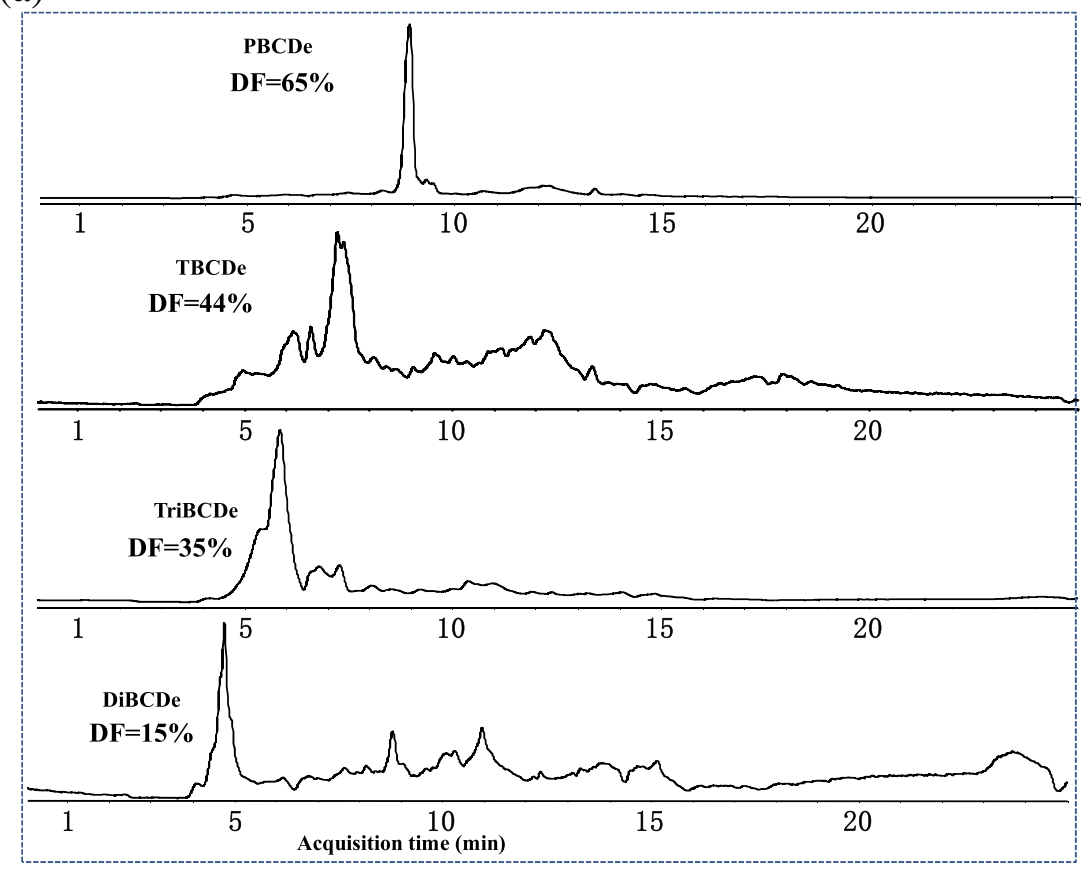

(b)

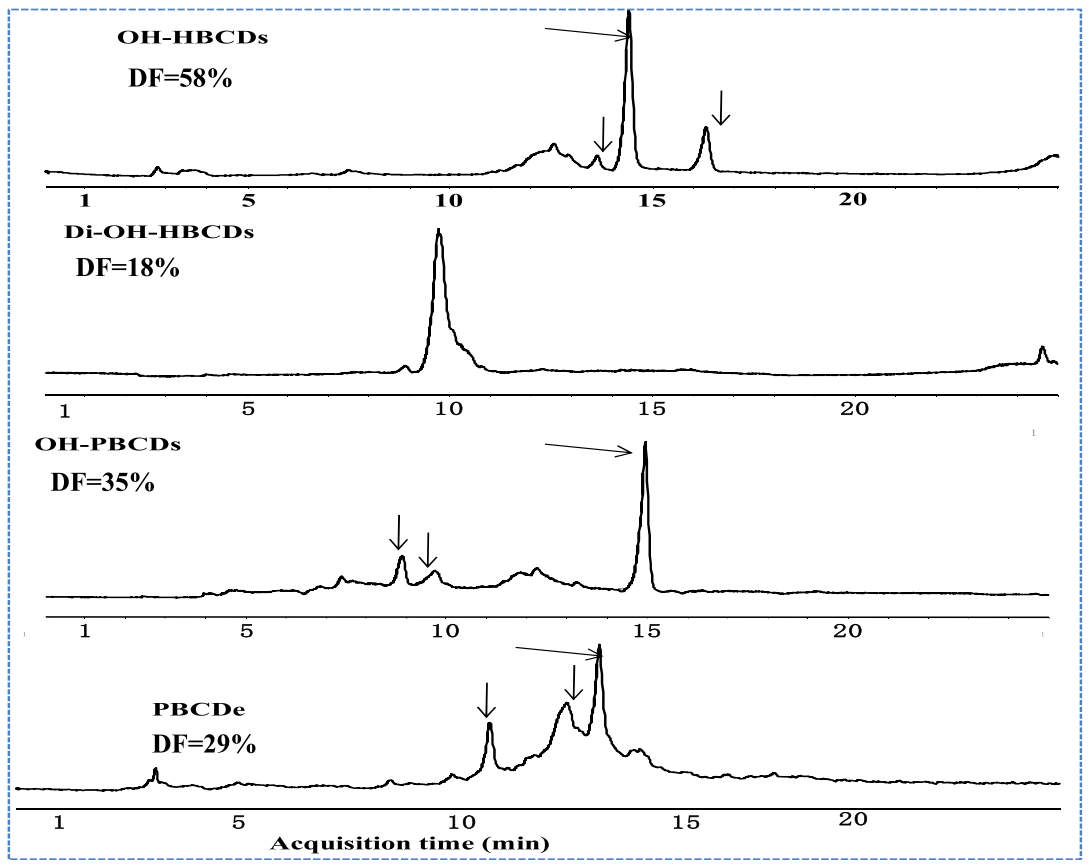


the change in EF values of chiral HBCDs was a good indicator of biological selectivity. In addition, concentrations of individual HBCD enantiomers (Fig. S2b) showed that $(-) \alpha-\mathrm{HBCD}$ was the most predominant isomers accumulated by all plants except wheat. Accumulation of HBCD enantiomers showed significant differences among plant species. For example, the $(-) \alpha-,(-) \beta-$, and $(+) \gamma-$ HBCDs accumulated to significantly higher levels in maize than their corresponding enantiomers, whereas, $(-) \alpha-,(+) \beta-$, and $(-) \gamma$-HBCDs accumulated at higher levels in wheat. The different bindings of enantiomers with plant biomacromolecules might be responsible for their selectivity in plants (Liu et al. 2009).

\section{Metabolization of HBCDs}

$[\mathrm{M}-\mathrm{H}]^{-}$brominated cluster peaks of pentabromocyclododecene (PBCDe, $m / z=558.3,560.3,562.3,564.3,566.3,568.3$ ), tetrabromocyclododecene (TBCDe, $\mathrm{m} / z=476.4,478.4$, 480.4, 482.4, 484.4, 486.4), tribromocyclododecene (TriBCDe, $m / z=398.6,400.6,402.6$, 404.6, 406.6, 408.6), and dibromocyclododecene (DiBCDe, $\mathrm{m} / \mathrm{z}=320.6,322.6$, 324.6, 326.6, 328.6, 330.6) were detected in soils. PBCDe isomers were the most frequently detected products with a detection frequency of $65 \%$, and detection frequencies of TBCDe, TriBCDe, and DiBCDe were 44, 35, and 15\%, respectively (Fig. $4 a$ ). In a biodegradation kinetics experiment, Davis et al. $(2005,2006)$ found that HBCD in wastewater sludge and freshwater aquatic sediment was sequentially debrominated via dihalo-elimination where at each step there is the loss of two bromines from vicinal carbons with the subsequent formation of a double bond between the adjacent carbon atoms. Results of our study also suggested degradation of HBCD via debromination also occurred in the soils from the plastic recycling areas. Two PBCDe, three monohydroxylated and one di-hydroxylated $\mathrm{HBCD}$ and three $\mathrm{OH}-$ PBCD isomers were identified in plant samples (Fig. 4b). Mono-OH-HBCDs were very commonly detected products with a detection frequency of $58 \%$. It has previously reported that mono- and di-hydroxyl HBCDs, debrominated metabolites including PBCDe and TBCDe, and HBCD-GSH adducts as degradation products of HBCDs in maize in a hydroponic experiment (Huang et al. 2016). Hydroxylation metabolites such as OH-PBCDs, OH-TBCDs, and OH-HBCDs were frequently reported on the biotransformation of HBCDs by liver microsomes (Zheng et al. 2015; Erratico et al. 2016). Debrominated products of PBCDs and TBCDs have been detected in milk from Bostan mothers and in indoor dust (Abdallah et al. 2008; Carignan et al. 2012). Furthermore, metabolization of HBCD by debromination and hydroxylation in organisms was enantio-specific and selective. Unfortunately, we could not distinguish which isomers were the metabolites derived from exposure to HBCD technical mixtures in the field experiment.

\section{Conclusion}

This study for the first time reported the occurrence, diastereomer and enantiomer profiles, and metabolization of HBCDs in soils and plants from sites with plastic waste contamination in China. HBCD concentrations followed the order plastic waste soil $>$ roadside soil $\geq$ farmland soil. The spatial distribution obviously indicates that plastic wastes disposal/recycling results in HBCDs release into soil and entering into the food chain. $\gamma$ HBCD presented as the dominant congener in soils, while $\alpha$ HBCD was preferentially accumulated in plants. HBCDs in farmland soil and all plant samples exhibited enantioselectivity based on the EFs. Debrominated products of TBCDe and PBCDe were identified in soils, and hydroxylated products of OH-HBCDs and OH-PBCDs were detected in plants. These results evidenced that HBCD contamination in the soil-plant system was caused by plastic waste, their stereoselectivity, and metabolization behavior. Since plastic waste has become the source for POPs, disposal and recycling of plastic wastes should be standardized. Measures to control toxic chemicals including HBCDs released from plastic wastes are urgent. In particularly, high pollution of HBCDs were observed in farmland soil; vegetables and crops near the plastic waste recycling area may indicate the potential risk to the local ecosystem and residents. Plastic waste disposal and recycling should be far away from the farmland. Vegetable and crop cultivation near the plastic waste recycling sites should be strictly avoided. Moreover, the finding that diastereomer and enantiomer-specific distribution of HBCDs, and their debrominated and hydroxylated metabolization occurred may help to understand the behaviors of HBCDs in the terrestrial environment. Future research is sorely needed to understand mechanisms of selective enrichment of HBCD stereoisomers and the cause of metabolization of HBCDs in soilplant system.

Acknowledgements We thank Dr. Rixiang Huang of Georgia Institute of Technology for his English polishing, comments and suggestions on the manuscript. This work was supported by the National Natural Science Foundation of China (Projects 21577155, 21537005, and 21621064) and the Strategic Priority Research Program of the Chinese Academy of Sciences (XDB14020202).

\section{References}

Abdallah MA, Ibarra C, Neels H, Harrad S, Covaci A (2008) Comparative evaluation of liquid chromatography-mass spectrometry versus gas chromatography-mass spectrometry for the determination of hexabromocyclododecanes and their degradation products in indoor dust. J Chromatogr A 1190:333-341

Alaee M, Arias P, Sjödin A, Bergman $\AA$ (2003) An overview of commercially used brominated flame retardants, their applications, their use patterns in different countries/regions and possible modes of release. Environ Int 29:683-689 
Avio CG, Gorbi S, Regoli F (2016) Plastics and microplastics in the oceans: from emerging pollutants to emerged threat. Mar Environ Res $1: 1-21$

Carignan CC, Abdallah MAE, Wu N, Heiger-Bernays W, McClean MD, Harrad S, Webster TF (2012) Predictors of tetrabromobisphenol-A (TBBP-A) and hexabromocyclododecanes (HBCD) in milk from Boston mothers. Environ Sci Technol 46:12146-12153

Cozar A, Echevarria F, Gonzalez-Gordillo JI, Irigoien X, Ubeda B, Hernandez-Leon S, Palma AT, Navarro S, Garcia-de-Lomas J, Ruiz A, Fernandez-de-Puelles ML, Duarte CM (2014) Plastic debris in the open ocean. Proc Natl Acad Sci U S A 111:10239-10244

Davis JW, Gonsior S, Marty G, Ariano J (2005) The transformation of hexabromocyclododecane in aerobic and anaerobic soils and aquatic sediments. Water Res 39:1075-1084

Davis JW, Gonsior SJ, Markham DA, Friederich U, Hunziker RW, Ariano JM (2006) Biodegradation and product identification of $\left[{ }^{14} \mathrm{C}\right]$ hexabromocyclododecane in wastewater sludge and freshwater aquatic sediment. Environ Sci Technol 40:5395-5400

Desborough JL (2011) Exploring the utility of chiral signatures to further understanding of soil-to-herbage tansfer of persistent organic pollutants (POPs). University of Birmingham, Birmingham

Du MM, Lin LF, Yan CZ, Zhang X (2012) Diastereoisomer- and enantiomer-specific accumulation, depuration, and bioisomerization of hexabromocyclododecanes in zebrafish (Danio rerio). Environ Sci Technol 46:11040-11046

Eguchi A, Isobe T, Ramu K, Tue NM, Sudaryanto A, Devanathan G, Viet PH, Tana RS, Takahashi S, Subramanian A, Tanabe S (2013) Soil contamination by brominated flame retardants in open waste dumping sites in Asian developing countries. Chemosphere 90:23652371

Erratico C, Zheng XB, van den Eede N, Tomy G, Covaci A (2016) Stereoselective metabolism of $\alpha$-, $\beta$-, and $\gamma$-Hexabromocyclododecanes (HBCDs) by human liver microsomes and CYP3A4. Environ Sci Technol 50:8263-8273

Gao ST, Wang JZ, Yu ZQ, Guo QR, Sheng GY, Fu JM (2011) Hexabromocyclododecanes in surface soils from e-waste recycling areas and industrial areas in south China: concentrations, diastereoisomer- and enantiomer-specific profiles, and inventory. Environ Sci Technol 45:2093-2099

Gregg TT, Kerri P, Tyler O, Thor H, Paul AH, Gordia M, Chris HM (2008) Enantioselective bioaccumulation of hexabromocyclododecane and congener-specific accumulation of brominated diphenyl ethers in an eastern Canadian Arctic marine food web. Environ Sci Technol 42: 3634-3639

Guerra P, Eljarrat E, Barceló D (2008) Enantiomeric specific determination of hexabromocyclododecane by liquid chromatographyquadrupole linear ion trap mass spectrometry in sediment samples. J Chromatogr A 1203:81-87

Hakk H, Letcher RJ (2003) Metabolism in the toxicokinetics and fate of brominated flame retardants - a review. Environ Int 29:801-828

Håkas M, Hylland K, Berge JA, Nygåd T, Mariussen E (2009) Spatial diastereomer patterns of hexabromocyclododecane (HBCD) in a Norwegian fjord. Sci Total Environ 407:5907-5913

He MJ, Luo XJ, Yu LH, Liu J, Zhang XL, Chen SJ, Chen D, Mai BX (2010) Tetrabromobisphenol-A and hexabromocyclododecane in birds from an e-waste region in South China: influence of diet on diastereoisomer- and enantiomer-specific distribution and trophodynamics. Environ Sci Technol 44:5748-5754

Heeb NV, Schweizer WB, Mattrel P, Haag R, Gerecke AC, Schmid P, Zennegg M, Vonmont H (2008) Regio- and stereoselective isomerization of hexabromocyclododecanes (HBCDs): kinetics and mechanism of $\gamma$ - to $\alpha$ - HBCD isomerization. Chemosphere 73:1201-1210

Heeb NV, Graf H, Schweizer WB, Lienemann P (2010) Thermallyinduced transformation of hexabromocyclododecanes and isobutoxypenta bromocyclododecanes in flame-proofed polystyrene materials. Chemosphere 80:701-708

Horton AA, Waltona A, Spurgeon DJ, Lahive E, Svendsen C (2017) Microplastics in freshwater and terrestrial environments: evaluating the current understanding to identify the knowledge gaps and future research priorities. Sci Total Environ 586:127-141

Huang HL, Zhang SZ, Lv JT, Wen B, Wang S, Wu T (2016) Experimental and theoretical evidence for diastereomer- and enantiomer-specific accumulation and biotransformation of HBCD in maize roots. Environ Sci Technol 50:12205-12213

KÖpen R, Becker R, Jung C, Nehls I (2008) On the thermally induced isomerisation of hexabromocyclododecane stereoisomers. Chemosphere 71:656-662

Law RJ, Kohler M, Heeb NV, Gerecke AC, Schmid P, Voorspols S, Covaci A, Becher G, Janák K, Thomsen C (2005) Hexabromocyclododecane challenges scientists and regulators. Environ Sci Technol 39: $281 \mathrm{~A}-287 \mathrm{~A}$

Le TT, Son MH, Nam IH, Yoon H, Kang YG, Chang YS (2017) Transformation of hexabromocyclododecane in contaminated soil in association with microbial diversity. J Hazard Mater 325:82-89

Li YN, Zhou QX, Wang YY, Xie XJ (2011) Fate of tetrabromobisphenol A and hexabromocyclododecane brominated flame retardants in soil and uptake by plants. Chemosphere 82:204-209

Liu WP, Ye J, Jin MQ (2009) Enantioselective phytoeffects of chiral pesticides. J Agric Food Chem 57:2087-2095

Lwanga EH, Gertsen H, Gooren H, Peters P, Salánki T, van der Ploeg M, Besseling E, Koelmans AA, Geissen V (2016) Microplastics in the terrestrial ecosystem: implications for Lumbricus terrestris (Oligochaeta, Lumbricidae). Environ Sci Technol 50:2685-2691

Marvin CH, MacInnis G, Alaee M, Arsenault G, Tomy GT (2007) Factors influencing enantiomeric fractions of hexabromocyclododecane measured using liquid chromatography/tandem mass spectrometry. Rapid Commun Mass Spectrom 21:1925-1930

Meng XZ, Duan YP, Yang C, Pan ZY, Wen ZH, Chen L (2011) Occurrence, sources, and inventory of hexabromocyclododecanes (HBCDs) in soils from Chongming Island, the Yangtze River Delta (YRD). Chemosphere 82:725-731

Ni HG, Lu SY, Mo T, Zeng H (2016) Brominated flame retardant emissions from the open burning of five plastic wastes and implications for environmental exposure in China. Environ Pollut 214:70-76

Palace VP, Pleskach K, Halldorson T, Danell R, Wautier K, Evans B, Alaee M, Marvin C, Tomy GT (2008) Biotransformation enzymes and thyroid axis disruption in juvenile rainbow trout (Oncorhynchus mykiss) exposed to hexabromocyclododecane diastereoisomers. Environ Sci Technol 42:1967-1972

Petersen M, Hamm S, Schäfer A, Esser U (2004) Comparative GC/MS and LC/MS detection of hexabromocyclododecane (HBCD) in soil and water samples. Organohalogen Compd 66:226-231

Rani M, Shim WJ, Han GM, Jang M, Song YK, Hong SH (2014) Hexabromocyclododecane in polystyrene based consumer products: an evidence of unregulated use. Chemosphere 110:111-119

Remberger M, Sternbeck J, Palm A, Kaj L, Strömberg K, BrorströmLundén E (2004) The environmental occurrence of hexabromocyclododecane in Sweden. Chemosphere 54:9-21

Susanne E, Roland B, Andreas MB, Wolfram B, Christian J, Irene N (2010) HBCD stereoisomer pattern in mirror carps following dietary exposure to pure $\gamma$-HBCD enantiomers. J Agric Food Chem 58: 9705-9710

Tang ZW, Huang QF, Cheng JL, Yang YF, Yang J, Guo W, Nie ZQ, Zeng N, Jin L (2014) Polybrominated diphenyl ethers in soils, sediments, and human hair in a plastic waste recycling area: a neglected heavily polluted area. Environ Sci Technol 48:1508-1516

Teuten EL, Saquing JM, Knappe DRU, Barlaz MA, Jonsson S, Björn A, Rowland SJ, Thompson RC, Galloway TS, Yamashita R, Ochi D, Watanuki Y, Moore C, Viet PH, Tana TS, Prudente M, Boonyatumanond R, Zakaria MP, Akkhavong 
K, Ogata Y, Hirai H, Iwasa S, Mizukawa K, Hagino Y, Imamura A, Saha M, Takad H (2009) Transport and release of chemicals from plastics to the environment and to wildlife. Philos Trans R Soc B 364:2027-2045

Thompson RC, Moore CJ, vom Saal FS, Swan SH (2009) Plastics, the environment and human health: current consensus and future trends. Philos Trans R Soc B 36:2153-2166

Velis CA (2014) Global recycling markets - plastic waste: a story for one player - China. Report prepared by FUELogy and formatted by Dwaste on behalf of International Solid Waste Association Globalisation and Waste Management Task Force. ISWA, Vienna, September 2014. Available online https:/www.iswa.org/fileadmin/ galleries/TaskForces/TFGWMReportGRMPlasticChinaLR.pdf. Accessed 21 June 2016

Wan WN, Zhang SZ, Huang HL, Wu T (2016) Occurrence and distribution of organophosphorus esters in soils and wheat plants in a plastic waste treatment area in China. Environ Pollut 214:349-353

Wong F, Kurt-Karakus P, Bidleman TF (2012) Fate of brominated flame retardants and organochlorine pesticides in urban soil: volatility and degradation. Environ Sci Technol 46:2668-2674

Wu JP, Guan YT, Zhang Y, Luo XJ, Zhi H, Chen SJ, Mai BX (2010) Trophodynamics of hexabromocyclododecanes and several other nonPBDE brominated flame retardants in a freshwater food web. Environ Sci Technol 44:5490-5495

Yu ZQ, Peng P, Sheng GY, Fu JM (2008) Determination of hexabromocyclododecane diastereoisomers in air and soil by liquid chromatography-electrospray tandem mass spectrometry. J Chromatogr A 1190:74-79

Zhai GS, Gutowski SM, Lehmler HJ, Schnoor JL (2014) Enantioselective transport and biotransformation of chiral hydroxylated metabolites of polychlorinated biphenyls in whole poplar plants. Environ Sci Technol 48:12213-12220

Zhang YW, Sun HW, Liu F, Dai YY, Qin XB, Ruan YF, Zhao LJ, Gan ZW (2013) Hexabromocyclododecanes in limnic and marine organisms and terrestrial plants from Tianjin, China: diastereomer and enantiomer-specific profiles, biomagnification, and human exposure. Chemosphere 93:1561-1568

Zhang H, Kuo YY, Gerecke AC, Wang J (2012) Co-release of hexabromocyclododecane (HBCD) and nano- and microparticles from thermal cutting of polystyrene foams. Environ Sci Technol 46:10990-10996

Zheng XB, Erratico C, Abdallah MAE, Negreira N, Luo XJ, Mai BX, Covaci A (2015) In vitro metabolism of BDE-47, BDE-99, and alpha-, beta-, gamma-HBCD isomers by chicken liver microsomes. Environ Res 143:221-228

Zhu HK, Sun HW, Zhang YW, Xu JY, Li B, Zhou QX (2016) Uptake pathway, translocation, and isomerization of hexabromocyclododecane diastereoisomers by wheat in closed chambers. Environ Sci Technol 50: 2652-2659

Zhu HK, Zhang K, Sun HW, Wang F, Yao YM (2017) Spatial and temporal distributions of hexabromocyclododecanes in the vicinity of an expanded polystyrene material manufacturing plant in Tianjin, China. Environ Pollut 222:338-347 